\title{
Three Misrepresentations of Logic
}

\section{Brian MacPherson University of Michigan \\ Ann Arbor \& Dearborn}

\begin{abstract}
Three misrepresentations of informal and formal logic by two feminist writers are discussed. Andrea Nye's criticism that the semantics for formal logic abstracts from context is a misrepresentation of formal logic because Nye ignores the development of intensional logics. Second, Nye's criticism that informal logicians ignore the origins of arguments is a misrepresentation of fallacy theory. Prominent writers in the field specifiy numerous cases where the origins of an argument are relevant to its evaluation. Third, Valerie Plumwood's criticism that negation in classical logic rests on an exclusivistic dualism that encourages the exclusion of women is shown to be false.
\end{abstract}

Résumé: On discute de trois présentations erronées de la logique formelle et non formelle dans les écrits de deux féministes. Premièrement, la critique d'Andrea Nye selon laquelle la sémantique de la logique formelle s'abstrait du contexte fausse la logique formelle parce que Ney ne tient pas compte des développements dans les logiques intensionnelles. Deuxièment, sa critique selon laquelle les logiciens non formels ignorent les origines des arguments dénature la theorie des sophismes. Les écrivains renommés dans ce champ identifient plusieurs cas où les origines d'un argument sont pertinentes à son évaluation. Troisièment, on démontre la fausseté de la critique de Valerie Plumwood selon laquelle la négation dans la logique classique repose sur un dualisme d'exclusion qui encourage l'exclusion des femmes.

Keywords: misrepresentation, logic, informal, formal, Nye, Plumwood

It is important that people working in both formal and informal logic from various fields are aware of the criticisms made against logic in the feminist literature. Some criticisms need to be taken seriously, and others need to be seen for what they are-misrepresentations of logic. It is not being claimed that all critiques of logic are misrepresentations. For example, the observation made by Maryann Ayim and by Trudy Govier that informal logic contains adversarial terms that imply violence such as "defense" and "opponent" should be taken seriously. The purpose here is to caution readers about some important criticisms of logic that are misrepresentations.

I am primarily a formal logician with interests in and a healthy respect for work being done in informal logic. I make no claims to being a scholar with respect to the informal logic literature nor with respect to the feminist literature. Nonetheless, I am very careful not to fall into Andrea Nye's trap of misrepresenting what informal logicians do or what feminist writers argue. The proof of this, as the reader 
will verify, is in the proverbial pudding. Further, this is not a formal logic article in disguise-Nye's criticisms and Ayim's and Govier's observations concerning the use of adversarial terms in logic bear directly on informal logic as well as formal logic. This article provides a service to both fields, and it is intended as such.

In particular, there are three misrepresentations of logic that need attention, two with respect to formal logic and one with respect to informal logic. First, based on the assumption that formal logic is to be identified only with classical two-valued logics that have extensional semantics, Andrea Nye has claimed that formal logic and its semantics ignore situations, people's desires, relations, intentions, and conflicts because they lack the expressive richness of natural language (Nye, 1990, pp. 2-3). This is true with respect to the classical propositional and predicate calculi. However, generalizations of modal logics such as illocutionary logics and Lewis' general semantics take into account contextual features such as agents, times, and intentions. Truth-values of propositions are evaluated relative to such contextual features. In this sense, Nye has misrepresented formal logic. Whether or not this undermines Nye's general reservations about logic is not my concern in this article, although what I say here will certainly put formal logic in a more charitable light.

Second, related to the above charge made against formal logic, Nye claims that the fallacy approach to evaluating arguments inappropriately ignores the origins of arguments. Truth-values of claims are seen to be independent of both the persons who put forward these claims and the surrounding circumstances. Nye counters that the characters of arguers are relevant to the consideration of their arguments (Nye, 1990, p. 174). For a more balanced portrayal of informal logic, she would have done well to mention that prominent writers in informal logic such as Ralph Johnson and J. Anthony Blair as well as Douglas Walton admit that there are often cases where the origins of an argument are relevant to its evaluation. Granted, these writers may not, with respect to the overall history of logic, have the prominence of the writers Nye discusses in her book such as Frege, but they have prominence in their field. It of course could be countered that Nye's discussion of informal logic has a peripheral role to play in her book. Nonetheless, this does not excuse Nye of the charge that she has misrepresented the fallacy-based approach to informal logic in the sense that, as with formal logic, she has ignored some noteworthy developments in that field.

One thing should be made perfectly clear at this point: 1 am not concerned with whether Nye's book builds an interesting description and critique of the history of logic. This is beyond the scope of this article. I am taking Nye to task about what she suggests about contemporary formal and informal logic. Further, it cannot be objected that Nye's criticisms are so misguided as to not deserve any serious attention. Afterall, there are many people out there who read feminist authors such as Nye, Harding, and Flax and who take what they say very seriously. I doubt that a reputable press like Routledge would have published Nye's book if they felt that Nye's views would not be given serious consideration by readers. Sometimes the 
most misguided criticisms can be the most devastating, and so I am hoping that I can diffuse these criticisms by exposing them for what they are: misrepresentations.

Third, although Valerie Plumwood recognizes that Nye has mistakenly identified formal logic with the classical propositional and predicate calculi, Plumwood misrepresents these logics as being oppressive. Unlike Nye, Plumwood maintains that the best antidote to oppressive classical logic is to adopt a nonstandard logic from among the plethora of alternative logics. Plumwood claims that the semantics of classical formal logic rests on an exclusivistic dualism (Plumwood, 1993, pp. 453-455). In classical logic, there are only two truth-values, viz., the true and the false and since classical negation is based on Boolean complementation, it encourages the exclusion of whatever is other than the proposition being negated. However, classical negation is not as exclusivistic as Plumwood makes it out to be.

Acknowledging that there are many kinds of logics that have nonclassical conceptions of negation, such as relevance logics, Plumwood suggests that these could serve as less oppressive alternatives to the classical logic of domination. Yet the same charges made against classical logic could with equal impropriety be made against relevance logics. If some nonstandard logics are to be endorsed as less oppressive than classical logic, a better choice would be multi-valued logics. Multivalued logics allow for three or more truth-values, so that there is no sharp true $/$ false dichotomy.

In what follows, the claim that logic has been misrepresented by some feminist critics is developed. Further, it is noted that logics such as quantum logics are not in any obvious way manifestations of the "patriarchy" in the sense of being attempts by powerful men to dominate people, but they are rather responses to the results of empirical investigation. Some authors charge that empirical investigation is itself suspect since it rests on unexamined cultural assumptions relating to gender biases. However, it is shown that this charge is unsubstantiated. Finally, I suggest that one of those criticisms of formal and informal logic that rings true does not necessitate the abandonment of logic.

\section{Putting logic into context: Nye's criticisms of formal and informal logic}

Nye suggests that formal logic involves the manipulation of $p$ 's and q's divorced from the relations, turmoils, and experiences of persons (Nye, 1990, pp. 2-3, p. 174). She claims that rather than stimulating thought, formal logic obviates thought since it presents us with a series of ready-made truths and relations divorced from the lives of persons. Further, she claims that logic with its presumption of authoritative situation-independent truth is oppressive in the sense that men use it to ensure that women converse with them on men's terms, thereby reaffirming men's power. Nye maintains that the "antidote" to the oppressiveness of logic is the 
richness of natural language (Nye, 1990, p. 176). Thus, contrary to writers such as Plumwood, Nye does not think that the remedy to oppressive logics is to invoke better logics. Her solution is to dispense with formal logic altogether. However, Nye has misrepresented formal logic by at least implicitly identifying it with the classical propositional and predicate calculi. She has ignored the existence of richer, intensional logics that take into account situations and contexts.

Nye's charges concerning the irrelevance and abstractedness of the classical propositional and predicate calculi are well founded; the classical propositional and predicate calculi are wholly inadequate for capturing the intricacies of natural language, which include references to modalities, situations, and contexts. One wonders why elementary logic texts insist on teaching translations. For example, alethic, epistemic, temporal, and deontic modalities have no rendering in the syntax of the classical propositional and predicate calculi. The statement "Nye believes that classical logic abstracts from situations" is translated simply as an atomic sentence letter in the propositional calculus. Thus, Nye's charge against formal logic would be a more serious charge if formal logic were merely the classical and predicate calculi. But alas, there are more logics in heaven and earth than are dreamt of in Nye's philosophy.

The syntax of alethic modal logics and their deontic, temporal, and epistemic variants accommodate the modalities of natural language. Thus, they have a richer expressive power than the classical propositional and predicate calculi, though granted, they still do not take into account contextual features in Nye's sense of 'context'. With respect to the model-theoretic semantics originally developed by Saul Kripke and Jaakko Hintikka that characterizes these systems, propositions are evaluated relative to indices. Intuitively, for alethic modal logics the indices are possible worlds, for tense logics they are times, for deontic logic they are ideal worlds, and so on. Further, there is nothing to prevent combining these systems. Montague grammars generalize on the notion of an index so that sentences are evaluated relative to ordered pairs consisting of worlds and times. Further, Montague proposes a logic that combines necessity and obligation (Montague, 1974, p. 111). However, generalizations of modal logics and Montague grammars do take into account contexts in Nye's sense of the term.

Like Richard Montague, David Lewis also generalizes on the notion of an index from the model-theoretic semantics for modal logics. Sentences according to Lewis's general semantics (which could be adapted for various possible languages or logics) are evaluated with respect to indices as n-tuples of coordinates that include not only possible worlds, but also contextual coordinates such as times, places, speaker-hearer contexts, and so on (Lewis, 1983, p. 195). The intension of a sentence according to this semantics is a function that takes as its arguments the sentence along with these various coordinates and has as its value a truth-value. Since indices in this type of semantics include reference to speakers and hearers, the corresponding logics that could be developed would also be able to accommodate speech acts. In fact, John Searle and David Vanderveeken have developed an 
illocutionary logic and semantics that accommodate speech acts. These logics and formal semantics therefore do not ignore contexts and situations unlike the simple extensional systems of the classical propositional and predicate calculi.

Nye's criticism of formal logic is therefore uncharitable by her lack of consideration of the many intensional logics that have been developed over the years; she obviously did not take these developments into account in constructing her critique of formal logic. Plumwood also acknowledges this fact (Plumwood, 1993, p. 440). An additional illustration will make this point even clearer. In her critique of Fregean logic, Nye claims that personal pronouns such as "I" and "she" are analyzed away in favor of definite descriptions (Nye, 1990, p. 154). This is true with respect to the classical predicate logic developed by Frege. However, Kaplan has developed a logic and a semantics for indexicals such as "I" and "she." Relative to this semantics, pronouns are not analyzed away in favor of definite descriptions.

Nye would probably not be appeased by the development of richer logics since she could still claim that even these abstract from situations and persons. Even the most complex formal logic will be artificial since it will at best approximate natural language. Any deviation from natural language is oppressive, and so there is no substitution for natural language. Also, generalizations of modal logics replace flesh and blood persons in real-life situations with lifeless mathematical entities. True, but some contemporary logics and semantics at the very least recognize that contextual features need to be taken into account, and so these logics are more expressively rich than extensional logics. This much should be noted; a truly representative account of formal logic ought to invite a reconsideration of its relative merits from a feminist perspective.

Related to her criticism of formal logic, Nye suggests that the discussion of the genetic fallacy in informal logic rests on the mistaken assumption that the origins of arguments are irrelevant to their evaluation. According to Nye, the genetic fallacy is characterized by informal logicians along the following lines (Nye, 1990, p. 174):

It is a fallacy to think that the genesis of an idea is relevant to its truth or falsity. It is a fallacy to think that a critical understanding of the person who holds a view can count against the truth of that view.

Contrary to this view, Nye maintains that an understanding of the character and circumstances of the arguer is relevant to considering the truth of his or her claim.

It is true that in fallacy theory, the genetic fallacy (any species of ad hominem or "against the person") is committed when the character or circumstances of the arguer are cited as reasons for rejecting his or her claim even though these factors are irrelevant to the truth of the claim in question. However, at least some of the more prominent writers in informal logic and critical thinking do not maintain that an understanding of the person cannot count against that person's views. Johnson and Blair (1994, pp. 102-104) as well as Walton (1989, p. 255) maintain that there will often be cases where the origins of a claim are relevant to its consideration. 
Johnson and Blair discuss several types of situations where it is legitimate to consider the character of the arguer. For example, they claim that it is legitimate to consider the character of someone running for political office who advances an argument: the views of someone running for political office who has a criminal past could appropriately be called into question on the basis of that person's past. They also argue that it is legitimate to cite a person's character in cases relating to credibility such as in courts of law. Hence, the testimony of a witness who is a habitual liar can be called into question in light of the witness's tendency to lie.

As another case in point, Walton provides the following definition of what a fallacy is: A fallacy is an argument that fails to meet some standard of correctness relative to a certain context of dialogue, although with respect to that context, the argument resembles one that does actually meet the standard of correctness. As Walton notes, "the context of dialogue is extremely important in determining whether a fallacy has been committed" (Walton, 1989, p. 257). Thus, there will be cases where ad hominem style argumentation is legitimate and there will be cases where it is not legitimate (as when, for example, there is nothing to substantiate someone's questions about a person's character). As another illustration of his account of fallacies, Walton argues that there will be cases where it is perfectly legitimate to appeal to sympathy (argumentum ad misercordiam) such as when trying to solicit donations for charities. The overall lesson to be drawn from Walton's theory of fallacies is that just because an arguer questions someone's character, or just because an arguer appeals to the sympathy of the listeners, and so on, it does not follow that any fallacy has been committed.

What is important about the fallacy approach to argumentation advanced by authors such as Walton as well as Johnson and Blair is that the criteria for the commission of the genetic fallacy are context-sensitive so that in some cases, the arguer's character and circumstances are relevant to assessing his or her argument.

\section{Plumwood on the logic of domination}

Plumwood recognizes that critics such as Nye mistakenly assume that formal logic can be identified with classical logic. Plumwood further recognizes that in the twentieth century, there has been a proliferation of nonclassical logics including multi-valued logics and relevance logics (Plumwood, 1993, p. 440). Arguably, many of these logics are "contained" in classical logics since the theses of these systems are subsets of the theses of classical logic, though as Susan Haack has pointed out, it is not a simple matter to say what exactly is the nature of the relationship between classical and non-classical logics (Haack, 1974 and Haack, 1978). In any case, basing a critique of logic on the assumption that logic is simply classical logic risks being beside the point. Plumwood believes that a better way of evaluating logic from feminist and other perspectives is to examine independently each of the different logics that exist (Plumwood, 1993, p. 441). She then goes on 
to argue that classical propositional and predicate logics are based on exclusivistic dualisms and are therefore "logics of domination." She further argues that alternatives to classical logic such as relevance logics are less oppressive.

According to Plumwood, the semantics of negation with its attendant true/ false dichotomy in classical propositional and predicate logics encourage oppressive dualisms such as male/female, mind/body, civilized/primitive, and so on. Plumwood claims that these dualisms, or what Tong calls binary oppositions (Tong, 1989 , p. 222 and p. 224), "reflect the major forms of oppression in western culture." (Plumwood, 1993, p. 443) They involve excluding the oppressed classes from full and equal participation in society. The dominant force or class can be read off from the first part of these dichotomies and the excluded classes can be read off from the second part of them. A case in point is the master/slave dichotomy.

Plumwood maintains that the major offender with respect to encouraging exclusivistic dualisms is the classical concept of negation; classical negation is simply Boolean complementation. The proposition $\sim p$ is the complement of the proposition $p$, so that $\sim p$ is simply whatever $p$ excludes. Thus, in a sense, negation divides the universe of propositions into those equivalent to $p$ and whatever is not equivalent to p. Further, Plumwood argues that negation as Boolean complementation does not distinguish between members of the complement class of a given proposition $\mathrm{p}$, and that this homogenization of the complementation class of the negated proposition is connected with a "binarism" that reflects the oppressive relations of such oppositions as master/slave (Plumwood, 1993, pp. 454-455).

However, Plumwood's criticism of classical negation misses the point because it misrepresents this type of negation. Negation does not divide the universe of propositions simply into $p$ and $\sim p$ propositions in the following sense: For any given proposition $p$, there will be an infinite number of propositions not logically equivalent to $p$ that are not the negations of $p$. In classical logic, a proposition $p$ is true if and only if its negation is false. However, for any proposition $p$, there are propositions that are not logically equivalent to it that do not have the attribute of being false if and only if $p$ is true. For example, if $p$ is $A \vee(B \supset C)$, then $\sim(A \vee C)$ is not logically equivalent to $\sim p$ although it certainly cannot be characterized as the negation of $p$ since there will be models that make both true. So with respect to any proposition $\mathrm{p}$, classical negation divides the universe of propositions into $\mathrm{p}$, $\sim p$, and anything not equivalent to either.

Even if we grant Plumwood's criticism of classical negation, classical negation is reversible unlike so-called oppressive binarisms in the following sense: The proposition $\sim p$ can itself be negated to obtain $\sim p$ or simply $p$. This dualism can be represented as $\sim p / \sim p$ or $\sim p / p$ where $\sim p$ is on the right-hand side of the dualism. Thus, from the point of view of $\sim p, p$ is excluded from $\sim p$. Then in terms of which proposition is "dominant," negation is neutral. So it is not clear that classical negation in any way reflects the oppressive dualisms of a patriarchal society, 
since these oppressive dualisms are not neutral-the right-hand side of the pair represents the dominant class. Thus, there is a clear disanalogy between the $p / \sim p$ duality and dualisms such as master/slave or male/female.

Now it could be objected that Plumwood is not referring to negation with respect to propositions but with respect to predicates pertaining to classes of things in predicate logic. That is, a predicate divides the universe into those things that fall under its extension and those that do not. Thus, in this sense of negation, classical negation does divide the universe into exclusive classes. Nonetheless, Plumwood uses lower case p's in her discussion of negation, which are understood by readers to refer to propositions, and not to predicates. This supports my reading of Plumwood on classical negation.

Further, what Plumwood ignores in her indictment of classical formal logic is the inclusive character of classical disjunction. In the semantics for propositional and predicate logic, a disjunctive proposition can be true even if both of its disjuncts are true. The exclusive "or" (i.e., "one or the other, but not both") is definable in terms of the inclusive "or" (i.e., "one or the other, or both") though in classical logic, the former is merely derivative and the latter is primary. This feature of classical disjunction does not in any clear way reflect societal dualisms whereby one of the members of the duality excludes the other. In fact, one could argue in favor of adopting classical two-valued logic as the logic of the oppressed because of this inclusive feature of classical disjunction.

Finally, a few words are in order concerning Plumwood's claim that relevance logic is closer to being egalitarian than is classical logic. Presumably, the intuitive idea here is that relevance logic is classical logic stripped of its oppressive overtones. Relevance logics simply "leave out" certain theses of classical logic such as "( $p \& \sim p) \supset q$ " that are divisive and exclusivistic. Plumwood claims that this particular thesis of classical logic is divisive and exclusivistic since it emphasizes the distance between $p$ (implicitly representing a dominant class) and its negation (implicitly representing an exploited class) or "other." The idea behind this classical thesis, claims Plumwood, is that if $p$ and its other were to be conjoined there would be an ultimate penalty to pay, which is "system collapse," given that anything is then derivable (Plumwood, 1993, p. 455). Correspondingly, in terms of the model-theoretic semantics for relevance logics developed by Routley and Meyer, relevance negation is "weaker" than classical negation so that relative to an index, or "set-up," $p$ and $\sim p$ can both be true. However, a closer examination of the semantics of relevance logics will indicate that they are no better suited to be logics of the oppressed than are classical logics and, in fact, the latter may be better suited to this purpose.

Relevance logics, like classical logics, have only two truth-values with respect to their semantics. Granted, the model-theoretic semantics for relevance logics are intensional in the sense that the connectives are not all straightforwardly truthfunctional. Propositions are evaluated relative to indices or set-ups (Routley and 
Meyer, 1973, p. 206). S. Read provides a more recent account of this indexical semantics for relevance logics (Read, 1989). Nonetheless, it remains the case that propositions can only take on one of two values relative to a set-up, viz., true or false. So if the true/false dichotomy of classical logic encourages oppression, so does the true/false dichotomy of relevance logics.

Second, although relevance negation is weaker than classical negation, the star function in relevance semantics requires that if $p$ is true at some set-up $W$, then $\sim p$ is false at some set-up or other $W^{*}$ that may or may not be $W$. Thus, while relevance logics tolerate inconsistencies with respect to a given set-up $\mathrm{W}$, they do not tolerate inconsistencies with respect to the entire logical space of set-ups (Routley and Meyer, 1973, p. 206). Crudely put, in the semantics for relevance logics, if $p$ is true somewhere, $\sim p$ must be false somewhere else.

Plumwood has a point. There is a plethora of logics out there, and there is no reason to focus on classical logic. However, classical logic cannot plausibly be rejected on the grounds that it is more oppressive than other sorts of two-valued logics such as relevance logics. The reason for considering nonstandard logics such as modal logics is that they are more realistic in the sense of taking into account contexts and situations, thus circumventing Nye's charge against formal logic. They do more justice to the richness of natural language.

It is worth mentioning that Plumwood would have done better to defend the view that multi-valued logics are to be preferred over two-valued logics, since their semantics avoid a true/false dichotomy. There are a variety of multi-valued logics ranging from those that allow three truth-values in their semantics to those allowing an infinite number of truth-values. To take a simple example, the system $\mathrm{L}_{3}$ has a semantics that allows for three truth-values that intuitively can be called "true," "false," and "indeterminate." Given the characteristic matrices for the connectives $\sim, \&, v, \supset$, and $\equiv$, the law of the excluded middle, "p $v \sim p$ " fails for this system. This is the sort of thesis that Plumwood would find offensive since it could be read as saying that any proposition $p$ can be only true or false, with no middle ground. But this is not a thesis of the system $\mathrm{L}_{3}$ : $\mathrm{p}$ can take a "middle" value, viz., indeterminate. Further, since three-valued implication is not definable in terms of disjunction and negation, the thesis $\mathrm{p} \supset \mathrm{p}$ is retained, making the system more plausible, since presumably any proposition implies itself. As will be noted in the next section, a three-valued logic was endorsed by physicist Hans Reichenbach as the characteristic logic of quantum mechanics.

\section{Empirical Logic}

Returning to Nye's critique of logic, she maintains that the development of formal logic was motivated by the inability of persons to deal with desperate situations in their society. In disintegrating societies where people were unable to effect change, formal logic served as a "substitute world" replete with abstract relations of implication and so forth. Further, Nye maintains that logic, with its conceptions of lawhood 
and authoritative truth, has been developed by powerful men to oppress others and to get rid of diversity among persons in society (Nye, 1990, p. 182). This is clearly a distortion of the motivations behind the development of at least some formal systems of logic. As a case in point, consider quantum logic, which was developed as a response to the empirical discoveries arising out of quantum mechanics. It did not arise in response to powerlessness with respect to a disintegrating society nor was it developed in order to discourage diversity or to dominate individuals. A brief consideration of the story behind the development of quantum logic should make this apparent.

Two approaches to quantum logic have been taken in the literature. The first was championed by physicist Hans Reichenbach in the 1930s. He maintained that a logic of quantum mechanics should have a three-valued semantics, viz., true, false, and indeterminate (Reichenbach, 1965, pp. 139-168). His development of this three-valued logic of quantum mechanics was motivated by the fact that observables or quantities such as position and momentum are incompatible in the sense that they cannot be jointly measured. Thus, if the position of a given particle has been determined, then a statement relating to its momentum would take on the value "indeterminate." This sort of logic was not the result of Reichenbach's alienation from the community or an attempt to dominate others, but was instead an attempt to take into account the empirical discovery that incompatible observables cannot have simultaneous values.

The import of Reichenbach's attempt to develop a quantum logic is that logic is empirical. Hilary Putnam took up this same theme and advocated a logic of quantum mechanics that is non-Boolean. In particular, he advocated a quantum logic that dispenses with the Boolean law of distribution, viz., $[(p \vee q) \& r] \equiv[(p \& r) v$ ( $q \& r$ )], given results such as those of the two-slit experiment (Putnam, 1975, pp. 174-197). In this experiment, a photon passing through two slits bombards a photographic plate. The probability of the photon hitting a tiny region $\mathrm{R}$ on the plate when both slits are open turns out to be nonclassical since it is not simply the sum of one-half the probability of hitting $R$ when only the first slit is open and onehalf the probability of hitting $\mathrm{R}$ when only the second slit is open. Putnam argues that the reason the expected classical probability does not agree with the observed probability is that the Boolean law of distribution is needed to derive the equation used in calculating the classical probability. Thus, Putnam argues that quantum logics should not contain the Boolean law of distribution. As with Reichenbach, Putnam's motivation for proposing quantum logic rests on considerations relating to empirical investigations.

It could be countered that I am here referring merely to the conscious and professed aims of quantum logicians, whereas these are not the only aims that Nye has in mind. Perhaps Nye sees all of this logical activity as the expression of deeper unconscious forces. However, barring a reason to believe that there are such forces (usually countenanced by allegedly patriarchal theories such as Freudian psychoanalysis), why should we assume that there is anymore going on than what 
the inventors of quantum logics say is going on? Why not take what they say at face value?

It could further be countered that although both Reichenbach and Putnam based their proposals for quantum logic on the results of empirical investigation, empirical investigation is itself suspect since it is laden with biases and hidden agendas such as the desire on the part of powerful men to subjugate others. Harding makes these sorts of charges against the natural sciences such as physics (Harding, 1986, ch. 4). Thus, indirectly at least, quantum logics are suspect given that they are responses to biased and oppressive practices.

Harding's charge against science can be answered by simply observing that she admits that many of the biases and hidden agendas presupposed by the "hard sciences" such as physics are undetected. Her "evidence" for biases existing in physics is indirect. For example, she argues that because biases have been found in the social sciences which have attempted to emulate the physical sciences by the use of statistics, it may be the case that they are reflecting similar biases in the physical sciences (Harding, 1991, p. 105). That is, the source of the biases may be the statistical methods they have adopted, and the attempt to quantify everything is a male-oriented approach. This argument is not terribly convincing. Perhaps the biases in the social sciences were there already and the statistical methods they adopted made these biases more apparent. It certainly does not follow that the social sciences were somehow infected with pre-existing biases from the physical sciences. Also, there are no a priori grounds for thinking that quantification is exclusively a male tendency.

Another indirect piece of evidence that one could cite to show that the physical sciences contain biases is the metaphorical use of allegedly gender-biased language by scientists in characterizing the progress in their fields. Ayim cites several historical and contemporary cases where scientists use such language (Ayim, 1988, p. 186). For example, scientists often talk about manipulating and controlling nature, where nature is a metaphor for being female, passive, and so forth. Also, she quotes from the physicist Richard Feynman where he likens accepting a theory to falling in love with a woman. Further, Ayim claims that "our scientific research will always be colored by our ideals, our metaphysics, and our metaphors" (Ayim, 1988 , p. 187). At this point, one might be tempted to go beyond Ayim's claim and conclude that this appeal to metaphors and similes by scientists belies a hidden agenda whose priority is the control and manipulation of females by males. However, such a conclusion is hasty, to say the least. Granted, our metaphorical language can influence the way we think to some extent (and I agree with Ayim that this is a reason for reconsidering the language that we use in logic) although this is a far cry from claiming that such language belies some insidious agenda or set of biases. The whole point of employing metaphorical language as well as similes is that one does not intend his or her statements to be taken literally. If a scientist says that accepting a theory is like falling in love with a woman, that person is not saying that accepting a theory is falling in love. Or, if a scientist says that the 
purpose of science is to control nature, that person is not assuming that there is an entity or person called 'nature' which needs to be controlled. Nor is the scientist literally saying that science is the control and manipulation of women, where the term 'nature' is a metaphor that refers to women.

Evelyn Fox Keller argues that although biases are detectable in more socially oriented sciences, with respect to "hard" sciences such as physics "a convincing case for the existence of a corresponding bias in either the design or interpretation of experiments has yet to be made" (Keller, 1991, p. 280). Granted, it does not follow from the failure to find biases that there are no such biases. On the other hand, Harding does not consider the alternative possibility that biases in the physical sciences are undetected because there are no such features to detect. At the very least, one should keep an open mind with respect to the existence of possible biases in the natural sciences such as physics without prejudging the issue one way or the other. Further, supposing it were the case that physics contains biases, it does not follow that these biases would be morally corrupt. There is a morally neutral sense of the term "bias" as well as a morally loaded sense of this term. To have a bias in the morally neutral sense means simply to have a point of view or perspective. There is nothing wrong with having a point of view or standpoint. On the other hand, the morally loaded sense of the term 'bias' is to be prejudicial to the point of harming others. The two senses of the term 'bias' was first made apparent to me by Professor J. Anthony Blair who heard an earlier version of this article. Also, Ayim herself notes that female researchers in science would bring in their own biases, although it need not follow that these biases are bad (A yim, 1988, p. 187). A similar analysis of the term "discrimination" has been offered by Thomas Hill in connection with another matter (Hill, 1991). In a morally neutral sense, "discrimination" can mean distinguishing objects from one another, whereas a morally loaded sense involves distinguishing between objects on irrelevant grounds such as hate or prejudice. There is no a priori reason to suppose that any undetected biases in the physical sciences will be biases in the morally loaded sense. I am not arguing that any biases that may exist in physics would be morally pure. Rather, I am saying that we should keep an open mind with respect to this issue.

The claim that physical science rests on undetected assumptions is unsubstantiated. P. K. Moser and J. D. Trout make a similar point (Moser and Trout, 1995). Further, even if such biases existed, it does not follow that they are morally corrupt. Thus, the objection that empirical investigation is suspect carries little weight as it stands. Granted, it is one's doxastic responsibility to keep an open mind. However, until the "evidence" begins pouring in, I see no reason to assume that the empirical research to which quantum logicians were responding was full of corrupt biases. 


\section{Concluding remarks: changing the language of logic}

To conclude, it has been shown that some feminist critiques of both formal and informal logic rest on misrepresentations of logic. It does not follow from these considerations that logic is beyond reproach. There is an additional critique of logic that rings true. As was mentioned, one such critique involves the claim that logicians employ adversarial terms such as "defense" and "attack." Use of these terms could convey the idea that the main purpose of argumentation is to win or to undermine the views of others. However, it does not follow from this observation that logic - formal or informal - should be abandoned, or that logicians have some hidden motive such as the need to dominate others anymore than scientists who speak of mastering nature need have an undetected agenda or corrupt bias. Metaphors such as "attack" and "defense" could either be abandoned or adumbrated without abandoning logic. This sort of proposal has been advanced by Ayim and later by Trudy Govier. Govier claims that there is no need to abandon logic or argumentation. Rather, she says that there can be approaches to studying argumentation that do not employ adversarial language. More specifically, she suggests that "there are alternative conceptual frameworks for thinking of argument, frameworks which are constructive and non-adversarial" (Govier, 1995, p. 204).

Along similar lines, Ayim maintains that we should not do away with critical thinking or argumentation. Rather, she claims that "in critical thinking classrooms, we can do our share to move society away from dominant confrontational paradigms toward affiliative cooperative paradigms" (Ayim, 1991, p. 85). Confrontational paradigms have as their goal to control and win through such techniques as cutting people off, using abusive language, and so on, whereas cooperative paradigms have as their goal to be inclusive and to nurture the views of others, while still maintaining standards of excellence in argumentation. Anyone who has attended a Philosophy conference has been exposed to the sort of counterproductive behaviour that results from employing the confrontational approach. Ayim notes that "nurturing goals, like any goals, assume the worth and the necessity for the striving for superiority" (Ayim, 1991, p. 80). Thus, there would still be a need for a theory of fallacies that would assess arguments and which could be used to detect flaws in reasoning-but for constructive ends. Also, there would still be a place for formal logic - even relative to a cooperative paradigm, it is perfectly acceptable to ask, where appropriate, whether the conclusion of someone's argument follows logically from its premises.

Taking the lead from Ayim and Govier, instead of having as a goal to always win arguments or to defend positions or to attack counterarguments, we could adopt a more inclusive goal which involves being able to recognize the arguments of others, to become familiar with other points of view, and not just to critically appraise them. Thus, from an affiliative/cooperative point of view, terms like "defense" and "attack" could be dropped or replaced with such terms as "understand" and "appraise." There is already a movement in this direction in the litera- 
ture. For example, Walton endorses a dialogical model of logic where arguments are not conceived as abstract sets of propositions that one attacks or defends but rather as taking place in the context of a dialogue between two parties. Certainly the notion of two parties having a dialogue is less adversarial than the notion of attacking or defending arguments. Also, Walton notes that not all dialogues are adversarial-some are collaborative (Walton, 1995, p. 28).

However, with all this said, my purpose here is not to develop a new nonadversarial model for formal and informal logic. There are others such as Ayim, Govier, and Walton who are eminently suited to the task. I am simply pointing out that there is a third alternative between adversarial logic and no logic at all. ${ }^{1}$

\section{Note}

' Many Thanks to William Massicotte, Ph.D. and to the late Hughes Leblanc, Ph.D. for their suport and encouragement during the initial writing of this article.

\section{References}

Ayim, M. 1988. "Violence and Domination as Metaphors in Academic Discourse" in Selected Issues in Logic and Communication, edited by Trudy Govier, Wadsworth, pp. 184-195.

Ayim, M. 1991. "Dominance and Affiliation: Paradigms in Conflict," in Informal Logic, Vol. XIII, No. 2, pp. 77-88.

Gilbert, M. 1994. "Feminism, Argumentation and Coalescence," in Informal Logic, Vol. XVI, No. 2, pp. 95-114.

Govier, T. 1995. "Non-adversarial conceptions of argument," in Proceedings of the Third ISSA Conference on Argumentation, Vol. I, pp, 196-206.

Haack, S. 1974. Deviant Logics. Cambridge: Cambridge University Press.

Haack, S. 1978. Philosophy of Logics. Cambridge: Cambridge University Press.

Harding, S. 1986. The Science Question in Feminism. Ithaca, NY: Cornell University Press

Harding, S. 1991. Whose Science? Whose Knowledge? Ithaca, NY: Cornell University Press.

Hill, T. 1991. "The Message of Affirmative Action," in Social Philosophy and Policy, 8, pp. $108-129$.

Johnson, R. H. and Blair, J. A. 1994. Logical Self-Defense. New York: McGraw-Hill.

Kaplan, D. 1979. "On the Logic of Demonstratives," in French, P. A., Uehling, Jr., T. E., and Wettstein H. K., eds. 1979. Minneapolis: University of Minnesota Press, pp. $401-412$.

Keller, E. F. 1991. "Feminism and Science," in Boyd, R., Gasper, P., and Trout, J.D., eds. The Philosophy of Science 1991. Cambridge, Mass.: The MIT Press, pp. 279-288.

Lewis, D. 1983. "General Semantics" in Philosophical Papers I. New York: Oxford University Press, pp. 189-229

Montague, R. 1974. Formal Philosophy. New Haven: Yale University Press. 
Moser, P.K. and Trout, J.D. 1995. "What is Feminist Epistemology?" in Informal Logic, Vol. 17, No. 1, pp. 101-111.

Nye, A. 1990. Words of Power. London: Routledge

Plumwood, V. 1993. "The Politics of Reason: Towards a Feminist Logic" in Australasian Journal of Philosophy, Vol. 71, No. 4, pp. 436-462.

Putnam, H. 1975. Philosophical Papers, Vol. I. Cambridge: Cambridge University Press.

Read, S. 1989. Relevant Logic. Oxford: Basil Blackwell.

Reichenbach, H. 1965. Philosophic Foundations of Quantum Mechanics. Berkeley: University of California Press.

Routley, R. and Meyer, R. K. 1973. "The Semantics of Entailment" in Leblanc, Hugues, ed., Truth, Syntax and Modality. Amsterdam: North-Holland Publishing Co., pp. 199-243.

Searle, J. and Vanderveeken, D. 1985. Foundations of Illocutionary Logic. Cambridge: Cambridge University Press.

Tong, R. 1989. Feminist Thought. San Francisco: Westview Press.

Walton, D. 1989. Informal Logic, Cambridge: Cambridge University Press.

Walton, D.1995. A Pragmatic Theory of Fallacy. University of Alabama Press: Tuscaloosa.

Dr. Brian MacPherson, 2337 Meighen Roa Windsor, Ontario, Canada N8W4B8 macphers@mnsi.net 